\title{
Communications
}

\section{Melamine Trisulfonic Acid as a New, Efficient and Reusable Catalyst for the Chemoselective Oxathioacetalyzation of Aldehydes}

\author{
F. Shirini* and J. Albadi \\ Department of Chemistry, College of Science, University of Guilan, Rasht-Iran. *E-mail: shirini@guilan.ac.ir \\ Received October 23, 2009, Accepted March 24, 2010
}

Key Words: Melamine trisulfonic acid, Aldehydes, 1,3-Oxathiolanes, Oxathioacetalyzation, Heterogeneous reaction conditions

\begin{abstract}
1,3-Oxathiolanes are synthetically important protecting groups for aldehydes due to their considerable stability under a variety of reaction conditions, ease of formation and removal, equality to acyl carbanions in $\mathrm{C}-\mathrm{C}$ bond forming reactions, ${ }^{1}$ and use in enantioselective synthesis of tertiary $\alpha$-hydroxy acids and glycols. $^{2}$
\end{abstract}

Usually the preparations of 1,3-oxathiolanes were carried out by the reaction of aldehydes with 2-mercaptoethanol under catalysis of reagents such as $\mathrm{HCl}_{1}{ }^{3} p-\mathrm{TsOH},{ }^{4} \mathrm{ZrCl}_{4},{ }^{5} \mathrm{HClO}_{4},{ }^{6}$ TMSOTf, ${ }^{7}$ OTAB $,{ }^{8} \mathrm{NBS},{ }^{9} \mathrm{TBAB},{ }^{10} \mathrm{MeS}_{2} / \mathrm{Br}_{2},{ }^{11} \mathrm{PAS},{ }^{12} \mathrm{PPS} /$ $\mathrm{SiO}_{2},{ }^{13} \mathrm{TaCl}_{5} / \mathrm{SiO}_{2},{ }^{14} \mathrm{MoO}_{2}$ (acac) ${ }_{2},{ }^{15}$ Alumina sulfuric acid, ${ }^{16}$ $\mathrm{Bi}\left(\mathrm{NO}_{3}\right)_{3},{ }^{17} \mathrm{Sn}\left(\mathrm{HPO}_{4}\right)_{2} \cdot \mathrm{H}_{2} \mathrm{O},{ }^{18}$ Amberlyst ${ }^{\circledR}-15,{ }^{19} \mathrm{Y}(\mathrm{OTf})_{3},{ }^{20} \mathrm{I}_{2},{ }^{21}$ $\mathrm{HBF}_{4}-\mathrm{SiO}_{2}{ }^{22}$ and $\mathrm{H}_{3} \mathrm{PW}_{12} \mathrm{O}_{40} / \mathrm{SiO}_{2}{ }^{23}$ However, many of these procedures suffer from one or more of the following dissadvantages: harsh reaction conditions, long reaction times, low yields, use of corrosive, expensive or moisture-sensitive reagents, destruction of the catalyst in work-up procedure, special efforts require to prepare the catalysts and tedious work-up procedure. Therefore, there is a scope to develop an alternative method for the protection of aldehydes as 1,3-oxathiolanes.

In recent years, the introduction of new reagents for the functional group transformations, became an important part of our research program. ${ }^{24-27}$ In continuation of these studies, herein, we wish to report the preparation of melamine trisulfonic acid, as a new catalyst (Scheme 1), and its application in the promotion of the oxathioacetalyzation of aldehydes with 2-mercaptoethanol. All reactions were performed in $n$-hexane at reflux temperature and under completely heterogeneous reaction conditions in excellent yields (Scheme 2, Table 1).

$$
\underset{(\mathrm{HO}) \mathrm{S})}{\stackrel{\mathrm{Neat}}{\longrightarrow}}
$$$$
\text { MTSA }
$$

Scheme 1

$$
\mathrm{RCHO} \underset{\mathrm{MTSA}(0.03 \mathrm{mmol}), n \text {-hexane, reflux }}{\mathrm{HSCH}_{2} \mathrm{CH}_{2} \mathrm{OH}(1.05 \mathrm{mmol})}
$$

Scheme 2
Optimization of the reaction conditions showed that the best results were obtained in refluxing $n$-hexane when the relative ratio of the substrate, 2-mercaptoethanol and MTSA was 1:1.05: 0.03 , respectively. After that, the different types of alehydes, including aliphatic and aromatic ones were subjected to oxathioacetalyzation under the determined conditions.

As shown in Table 1, all types of the above mentioned substrates were efficiently converted to their corresponding 1,3oxathiolanes in good to high yields during relatively short reaction times. It is very important to note that the progress of the reaction is so depends to the presence of MTSA in the reaction mixture, that the reaction did not proceed in the absence of this reagent even after prolonged heating (Table 1, entry 11). Because of the stability of ketones under the above mentioned conditions (Table 1, entries 14, 15), the reported method can be used for the chemoselective oxathioacetalyzation of aldehydes in

\begin{tabular}{|c|c|c|c|c|}
\hline Entry & Substrate & Time (min) & Yield (\%) & Reference \\
\hline 1 & $\mathrm{PhCHO}$ & 7 & 92 & 15 \\
\hline 2 & $2-\mathrm{NO}_{2} \mathrm{C}_{6} \mathrm{H}_{4} \mathrm{CHO}$ & 3 & 90 & 12 \\
\hline 3 & $4-\mathrm{NO}_{2} \mathrm{C}_{6} \mathrm{H}_{4} \mathrm{CHO}$ & 4 & 87 & 21 \\
\hline 4 & $4-\mathrm{CNC}_{6} \mathrm{H}_{4} \mathrm{CHO}$ & 15 & 75 & 21 \\
\hline 5 & $2-\mathrm{ClC}_{6} \mathrm{H}_{4} \mathrm{CHO}$ & $5(7,10)^{c}$ & $90(87,85)^{c}$ & 29 \\
\hline 6 & $4-\mathrm{ClC}_{6} \mathrm{H}_{4} \mathrm{CHO}$ & 6 & 90 & 11 \\
\hline 7 & 4- $\mathrm{BrC}_{6} \mathrm{H}_{4} \mathrm{CHO}$ & 5 & 95 & 13 \\
\hline 8 & $4-\mathrm{MeC}_{6} \mathrm{H}_{4} \mathrm{CHO}$ & $18(20,24)^{c}$ & $92(90,90)^{c}$ & 14 \\
\hline 9 & $4-\mathrm{MeOC}_{6} \mathrm{H}_{4} \mathrm{CHO}$ & 28 & 90 & 21 \\
\hline 10 & $2-\mathrm{MeOC}_{6} \mathrm{H}_{4} \mathrm{CHO}$ & 35 & 85 & 29 \\
\hline 11 & $\mathrm{PhCHO}$ & 30 & $0^{d}$ & - \\
\hline 12 & $\mathrm{PhCH}_{2} \mathrm{CH}_{2} \mathrm{CHO}$ & 19 & 90 & 14 \\
\hline 13 & $\mathrm{CH}_{3}\left(\mathrm{CH}_{2}\right)_{3} \mathrm{CHO}$ & 21 & 85 & 21 \\
\hline 14 & & 45 & $0^{e}$ & - \\
\hline 15 & $\mathrm{Ph}_{2} \mathrm{CO}$ & 60 & $0^{e}$ & - \\
\hline 16 & $\mathrm{PhCHO}+\mathrm{Ph}_{2} \mathrm{CO}$ & 10 & $100^{f}+0^{f}$ & - \\
\hline
\end{tabular}

Table 1. MTSA catalyzed formation of 1,3-oxathiolanes ${ }^{a, b}$

${ }^{a}$ Products were identified spectroscopically and also by the conversion of 1,3-oxathiolanes to the parent aldehydes. ${ }^{b}$ Isolated yields. ${ }^{c}$ Results obtained using recycled catalyst for the second and third times, respectively. ${ }^{d} \mathrm{Re}-$ action was performed in the absence of MTSA. ${ }^{e}$ Starting material recovered intact. ${ }^{f}$ Conversion. 
Table 2. Comparison of the efficiency of MTSA in the oxathioacetalyzation of benzaldehyde, with other reported methods

\begin{tabular}{cccccc}
\hline Entry & Reagent & Catalyst load $(\mathrm{mg})$ & Time (min) & Yield (\%) & Reference \\
\hline 1 & $\mathrm{Al}_{2} \mathrm{O}_{3}-\mathrm{SO}_{3} \mathrm{H}$ & 50 & $7(\mathbf{h})$ & 91 & 16 \\
2 & $\mathrm{HBF}_{4} \cdot \mathrm{SiO}_{2}$ & 50 & 8 & 94 & 22 \\
3 & ${\mathrm{Bi}\left(\mathrm{NO}_{3}\right)_{3}}^{\mathrm{MoO}_{2}\left(\mathrm{acac}_{2}\right.}$ & 40 & $5(\mathbf{h})$ & 75 & 17 \\
4 & $\mathrm{Amberlyst}^{\mathbb{B}}-15$ & 22 & 240 & 86 & 15 \\
5 & $\mathrm{Sn}\left(\mathrm{HPO}_{4}\right)_{2} \cdot \mathrm{H}_{2} \mathrm{O}$ & 17 & 60 & 84 & 19 \\
6 & $\mathrm{Y}(\mathrm{OTf})_{3}$ & 135 & 110 & 96 & 20 \\
7 & $\mathrm{MTSA}$ & 11 & 7 & 99 & Present method \\
8 & & & & 92 & 20
\end{tabular}

the presence of ketones (Table 1, entry 16).

Our investigations clarified that MTSA is reusable for three times (Table 1, entries 5, 8). The same IR spectra of the reagent were obtained before and after its use in the reactions, which demonstrates the stability of its composition.

In order to show the efficiency of this method, Table 2 compares the results from the oxathioacetalyzation of benzaldehyde in the presence of MTSA and some of the other catalysts.

In conclusion, we developed an efficient and high yielding method for the chemoselective oxathioacetalyzation of aldehydes. Relatively short reaction times, high efficiency, heterogeneous reaction conditions, availability and recyclability of the reagent and easy work-up are among the other advantages of this method, which make this procedure a useful and attractive addition to the available methods. We are exploring further applications of MTSA for the other types of functional group transformations in our laboratory.

\section{Experimental}

Preparation of MTSA. A $250 \mathrm{~mL}$ suction flask charged with chlorosulfonic acid $(5 \mathrm{~mL}, 75.2 \mathrm{mmol})$ was equipped with a gas inlet tube for conducting $\mathrm{HCl}$ gas overran adsorbing solution i. e. water. Melamine (3.16 g, $25.07 \mathrm{mmol}$ ) was added in small portions over a period of $30 \mathrm{~min}$ at room temperature. $\mathrm{HCl}$ gas evolved from reaction vessel immediately (Scheme 1). After completion of the addition of melamine, the mixture was shaken for $30 \mathrm{~min}$, meanwhile, the residual $\mathrm{HCl}$ was exhausted by suction. The mixture was triturated with $n$-hexane $(10 \mathrm{~mL})$ and then filtered. The solid residue was washed with $n$-hexane $(10 \mathrm{~mL})$ and dried under vacuum. Melamine trisulfonic acid (7.9 g, 87\%) was obtained as a white solid, which was stored in a capped bottle. mp $142-144{ }^{\circ} \mathrm{C}$; IR v 3133, 2621, 1654, 1509, 1175 , $1069 \mathrm{~cm}^{-1}$; Anal calcd for $\mathrm{C}_{3} \mathrm{H}_{6} \mathrm{~N}_{6} \mathrm{O}_{9} \mathrm{~S}_{3}(366.3): \mathrm{C}, 9.83 \%$; , $22.95 \%$; H, 1.64\%. Found: C, 9.81\%; N, 22.95\%; H, 1.64\%. The presence of three atoms of sulfur per each molecule of MTSA is confirmed by the titration of MTSA in acetonitrile media with $1.0 \mathrm{MBu}{ }_{4} \mathrm{NOH}(\mathrm{MeOH})$, according to the previously reported method. ${ }^{28}$

General procedure. A mixture of the substrate (1 mmol), 2mercapto ethanol (1.05 mmol) and MTSA (0.03 mmol, $0.011 \mathrm{~g})$ in $n$-hexane was stirred at reflux temperature. The progress of the reaction was monitored by TLC. On completion the solvent was evaporated, $\mathrm{CH}_{2} \mathrm{Cl}_{2}(5 \mathrm{~mL})$ was added and filtered. The solid residue was washed with $\mathrm{CH}_{2} \mathrm{Cl}_{2}(5 \mathrm{~mL})$ and then dried; the recovered catalyst can be used for two reactions again.
The organic layer was washed with saturated $\mathrm{NaHCO}_{3}$, then with water and dried over $\mathrm{MgSO}_{4}$. Evaporation of the solvent followed by column chromatography on neutral silica gel gave the requested 1,3-oxathiolan in excellent yields. Spectroscopic data are in agreement with previously reported. ${ }^{11-15,21,29}$

Acknowledgments. We are thankful to the University of Guilan Research Council for the partial support of this work.

\section{References}

1. Eliel, E. L.; Morris-Natschko, S. J. Am. Chem. Soc. 1984, 106, 2937.

2. Frye, S. V.; Eliel, E. L. Tetrahedron Lett. 1985, 26, 3907.

3. Ralls, J. W.; Dodson, R. M.; Riegel, B. J. Am. Chem. Soc. 1949, 71,3320

4. Djerassi, C.; Gorman, M. J. Am. Chem. Soc. 1953, 75, 3704.

5. Karimi, B.; Seradj, H. Synlett 2000, 805.

6. Mondal, E.; Sahu, P. R.; Khan, A. T. Synlett 2002, 463.

7. Ravindaranath, T.; Chavan, S. P.; Dantale, S. W. Tetrahedron Lett. 1995, 36, 2285.

8. Mondal, E.; Sahu, P. R.; Bose, G.; Khan, A. T. Tetrahedron Lett. 2002, 43, 2843.

9. Kamal, A.; Chouhan, G.; Ahmed, A. Tetrahedron Lett. 2002, 43, 6947.

10. Ranu, B. C.; Das, A. Aus. J. Chem. 2004, 57, 605.

11. Khan, A. T.; Sahu, P. R.; Majee, A. J. Mol. Catal. A: Chem. 2005, 226, 207.

12. Majee, A.; Kundu, S. K.; Islam, S. Synth. Comuun. 2006, 36, 3767.

13. Aoyama, T.; Takido, T.; Kodomari, M. Synlett 2004, 2307.

14. Chandrasekhar, S.; Prakash, J. S.; Shyamsunder, T.; Ramachander, T. Synth. Commun. 2005, 35, 3127.

15. Rana, K. K.; Guin, C.; Jana, S.; Roy, S. C. Tetrahedron Lett. 2003, $44,8597$.

16. Shaterian, A. R.; Hosseinian, A.; Ghashang, M. Synth. Commun. 2008, 38, 4097.

17. Nrivastava, N.; Dasgupta, S. K.; Banik, B. K. Tetrahedron Lett. 2003, 44, 1191.

18. Hazarika, P.; Sharma, S. D.; Konwar, D. Catal. Commun. 2008, 9 , 2389.

19. Ballini, R.; Bosica, G.; Maggi, R.; Mazzaczani, A.; Righi, P.; Sartori, G. Synthesis 2001, 1826.

20. Kanta De, S. Tetrahedron Lett. 2004, 45, 2339.

21. Bandgar, B. P.; Bettigeri, S. V. J. Chem. Res. (S) 2004, 389.

22. Kamble, V. T.; Bandgar, B. P.; Muley, D. B.; Joshi, N. S. J. Mol. Catal. A: Chem. 2007, 268, 70.

23. Firouzabadi, H.; Iranpoor, N.; Jafari, A. A.; Jafari, M. R. J. Mol. Catal. A: Chem. 2006, 247, 14.

24. Shirini, F.; Zolfigol, M. A.; Salehi, P.; Abedini, M. Current Org. Chem. 2008, 12, 183.

25. Shirini, F.; Zolfigol, M. A.; Paktinat, M. Synthesis 2006, 4252.

26. Shirini, F.; Abedini, M. J. Iran. Chem. Soc. 2008, 5 , S87.

27. Shirini, F.; Zolfigol, M. A.; Safari, A. J. Chem. Res. (S) 2006, 154.

28. Izutsu, K.; Yamamoto, H. Talanta 1998, 47, 1157.

29. Liang, X.; Gao, S.; Yang, J.; He, M. Catal. Commun. 2008, 10, 156. 